University of Wollongong

Research Online

Australian Institute for Innovative Materials -

Papers

Australian Institute for Innovative Materials

$1-1-2019$

Electro-polymerized polypyrrole film for fabrication of flexible and slurryfree polypyrrole-sulfur-polypyrrole sandwich electrode for the lithium-sulfur battery

Mohammad R. Kaiser

University of Wollongong, Commonwealth Scientific and Industrial Research Organization, mrkaiser@uow.edu.au

Zhaojun Han

Commonwealth Scientific and Industrial Research Organization, University of New South Wales

Jiazhao Wang

University of Wollongong, jiazhao@uow.edu.au

Follow this and additional works at: https://ro.uow.edu.au/aiimpapers

Part of the Engineering Commons, and the Physical Sciences and Mathematics Commons

Research Online is the open access institutional repository for the University of Wollongong. For further information contact the UOW Library: research-pubs@uow.edu.au 


\title{
Electro-polymerized polypyrrole film for fabrication of flexible and slurry-free polypyrrole-sulfur-polypyrrole sandwich electrode for the lithium-sulfur battery
}

\author{
Abstract \\ Thin films of polypyrrole (PPy) were electrochemically synthesized from direct oxidation of pyrrole (Py) \\ which is a five-membered ring heterocyclic aromatic compound with a dipole moment of 1.58D. The \\ electro-polymerized PPy thin film shows sufficiently good mechanical properties to be included in a self- \\ supporting free-standing layered cathode. Physical and morphological characterizations show that this \\ PPy film is flexible, robust, lightweight, corrugated, and highly conductive. These properties facilitate the \\ use of PPy thin film in a self-supported flexible electrode composed of slurry-free PPy-sulfur-PPy \\ sandwiched structure. Because the conventional slurry casting method could be avoided, a large amount \\ of active material could be loaded in between the corrugated PPy films. The newly developed flexible PPy- \\ sulfur-PPy sandwiched electrode thus show high capacity when coupled with lithium, along with good \\ cycling performance and excellent capacity retention. \\ Disciplines \\ Engineering | Physical Sciences and Mathematics

\section{Publication Details} \\ Kaiser, M. Rejaul., Han, Z. \& Wang, J. (2019). Electro-polymerized polypyrrole film for fabrication of flexible \\ and slurry-free polypyrrole-sulfur-polypyrrole sandwich electrode for the lithium-sulfur battery. Journal of \\ Power Sources, 437 226925-1-226925-8.
}




\title{
Electro-polymerized Polypyrrole Film for Fabrication of Flexible and Slurry-free Polypyrrole-Sulfur-Polypyrrole Sandwich Electrode for the Lithium-Sulfur Battery
}

\author{
Mohammad Rejaul Kaiser ${ }^{\mathrm{a}, \mathrm{b} *}$ Zhaojun Han $^{\mathrm{a}, \mathrm{c}, \mathrm{d}}$, Jiazhao Wang ${ }^{\mathrm{b} *}$
}

${ }^{a}$ CSIRO, Manufacturing, P.O. Box 218, 36 Bradfield Road, Lindfield, NSW 2070, Australia.

${ }^{\mathrm{b}}$ Institute for Superconducting and Electronic Materials, University of Wollongong, Wollongong, NSW 2522, Australia

c School of Chemical Engineering, The University of New South Wales, Kensington, New South Wales 2052, Australia.

${ }^{\mathrm{d}}$ School of Mechanical and Manufacturing Engineering, The University of New South Wales, Kensington, New South Wales 2052, Australia

*Corresponding author, Tel: +61 294137088

E-mail: rejaul.kaiser@csiro.au

jiazhao@uow.edu.au 


\begin{abstract}
Thin films of polypyrrole (PPy) were electrochemically synthesized from direct oxidation of pyrrole (Py) which is a five-membered ring heterocyclic aromatic compound with a dipole moment of 1.58D. The electro-polymerized PPy thin film shows sufficiently good mechanical properties to be included in a self-supporting free-standing layered cathode. Physical and morphological characterizations show that this PPy film is flexible, robust, lightweight, corrugated, and highly conductive. These properties facilitate the use of PPy thin film in a self-supported flexible electrode composed of slurry-free PPy-sulfur-PPy sandwiched structure. Because the conventional slurry casting method could be avoided, a large amount of active material could be loaded in between the corrugated PPy films. The newly developed flexible PPy-sulfur-PPy sandwiched electrode thus show high capacity when coupled with lithium, along with good cycling performance and excellent capacity retention.
\end{abstract}

Keywords: Electro-polymerization; Polypyrrole film; PPy-sulfur-PPy sandwiched electrode; Slurry-free electrode. 


\section{Introduction:}

The quest for energy storage devices with high energy density is one of the most highly topical areas for researchers all over the world due to the emergence of new portable electronic devices, and of hybrid and electric vehicles into our daily lives[1]. It is believed that the lithium-sulfur battery is the best possible candidate for next-generation high energy storage systems because it has the highest theoretical energy density (2600 Wh/kg) [2]. Moreover, sulfur is easily available, low-cost, and non-toxic. In comparison to electrode materials with a two-electron transfer per atom, sulfur shows the highest theoretical capacity (1675 mAh/g) among all the solid cathode materials [3-6]. Nevertheless, the poor electrical conductivity of sulfur, along with the dissolution of longer chain polysulfides into the electrolyte, and the changes in volume during the sulfur to sulfide transformation are obstructing its progress.

To overcome the aforementioned challenges, extensive research has been conducted on different conductive carbons, polymers, additives, binders, and electrolytes, along with engineered cathode materials, and on different techniques to load sulfur while maintaining the structural integrity of the electrode [7-11]. In most of the published works on sulfurcarbon cathode composite, the cathode was prepared from a sulfur and conductive carbon containing slurry that was later painted on a metal (in most cases on aluminum) foil [12-16]. This electrode preparation method may solve the insulation problem of sulfur, but it fails to address the dissolution phenomenon and volume expansion behavior. It has been found that, in most cases, conventional electrodes undergo structural disintegration and cracks due to volume expansion of the active material [17]. Moreover, in this process, a large proportion ( around 50\%) of the slurry consists of inactive materials, such as binder (e.g., polyvinylide difluoride (PVDF) and carboxymethyl cellulose (CMC)), solvents (e.g., N-methyl-2pyrrolidone (NMP)), and other conductive additives, and in some cases, the active material 
content is reduced to $30-40 \mathrm{wt} \%$ to accommodate the various additives. On top of that, if we consider the weight of the current collector, the active material content will drop down to 10 wt $\%$. It has been found that, among these inactive materials, the binder has some adverse effects on cell performance. Most of the binders are insulating by nature and increase the internal resistance of the cell. Moreover, at high temperature, binders (e.g. PVDF) decompose into toxic compounds (e.g. hydrofluoric acid, fluorocarbons, etc.) $[18,19]$. The recent study of Cui's group [20] shows that lithiation of sulfur during discharge detaches lithium sulfide $\left(\mathrm{Li}_{2} \mathrm{~S}\right)$ from the conductive carbon surface due to the low binding energy between the nonpolar carbon and the polar $\mathrm{Li}_{2} \mathrm{~S}$, which causes loss of electrical contact between the carbon and the active material, and results in capacity decay.

To minimize the volume expansion and polysulfide dissolution problems, researchers have focused on conductive polymers along with nitrogen-doped conductive carbons. The conductive polymers can ameliorate the volume expansion due to their high elasticity and flexibility, while nitrogen-doped conductive carbons that have a lone pair electron have a high tendency to form bonds with polar polysulfide species, thus reducing the polysulfide dissolution phenomenon [20-22]. Introducing conductive polymer instead of carbon into the sulfur electrode is not a new idea and has been under research for a decade to improve the cycling performance and capacity retention of the Li/S battery. Different conducting polymer composites, such as polythiophene [23], polyaniline [24], poly(3,4-ethylenedioxythiophene)poly(styrene sulfonate) [25], and polypyrrole [26] have been meticulously studied to enhance the performance of the lithium-sulfur(Li/S) system. Among these conducting polymers, polypyrrole (PPy) is the most widely adopted material in the Li/S battery system due to its facile and diversified polymerization method and in addition, because having a nitrogen atom with a lone pair electron in its ring has an added advantage for capturing polysulfides [27]. Although different conductive polymers and their composites have been used along with 
conductive carbons to synthesize sulfur-based cathode, there have been no initiatives to use the PPy film on its own as a current collector, where commercial sulfur or slurry-free sulfur composite would be directly loaded onto the PPy film. Considering all the facts, it will be a great milestone if conducting polymer can replace all the inactive materials in the electrode, including the current collector.

Recently, our group synthesized a flexible free-standing PPy film via the electropolymerization method, which was physically, thermally, and morphologically characterized $[28,29]$. The fabricated PPy film was only examined for its transport properties with respect to salt, however. Herein, we report the electro-polymerization of pyrrole to fabricate a PPy free-standing layer (FSL) with a corrugated surface morphology, which was later employed in a self-supported slurry-free sulfur-containing flexible electrode. Afterwards, two selfsupported slurry-free sulfur containing electrodes were attached together through mechanical pressing to form a PPy-sulfur-PPy flexible sandwich structure. Like all other sandwich structured electrode, this PPy-sulfur-PPy sandwich electrode not only facilitates to incorporate high amount active material loading but also act as a barrier to minimize polysulfides shuttling along with design flexibility and high areal capacity. It is believed that the newly developed flexible sandwich electrode can improve the electrochemical performance of the Li/S battery by ameliorating the volume expansion and polysulfide dissolution problems. For further study and comparing the performance, a small amount (10 wt\%) of PPy fiber was added to commercial sulfur to fabricate a sulfur-PPy fiber composite to increase the conductivity of the sulfur and to increase lithium ion transport to the cathode of the fabricated PPy-sulfur-PPy sandwich electrode.

\section{Experimental:}


2.1 Synthesis of PPy flexible free-standing film: In a beaker, a solution of $0.2 \mathrm{M}$ pyrrole and $0.05 \mathrm{M}$ p-toluene-sulphonate sodium salt ( $p$ TSNa) was prepared for electropolymerization. A stainless-steel plate $\left(9.5 \times 5.4 \mathrm{~cm}^{2}\right)$ acted as the working electrode, a reticulated vitreous carbon tube acted as counter electrode, and an $\mathrm{Ag} / \mathrm{AgCl}$ reference electrode was inserted into the beaker. An automatic battery testing system (Land ${ }^{\circledR}$, China) was used to apply different current densities with a fixed $14.4 \mathrm{C} / \mathrm{cm}^{2}$ charge density for the electro-polymerization. After electro-polymerization, the PPy free-standing film was easily peeled off from the stainless-steel plate and washed with distilled water and ethanol, which was followed by room temperature drying. It should be mentioned that all the chemicals were bought from Sigma Aldrich and directly used without further purification in the experiment, and the only exception was pyrrole, which was purified to $99.9 \%$ before use.

2.2 Fabrication of PPy fiber: The oxidative chemical polymerization method was used for the fabrication of PPy fibers. First, $0.3 \mathrm{~g}$ liquid Py monomers and $0.25 \mathrm{~g}$ pTSNa were dispersed in a $26 \mathrm{mM}$ cetyltrimethylammonium bromide (CTAB) solution, which acted as an aqueous surfactant. Then, $1 \mathrm{~g}$ ammonium persulfate (an oxidizing agent) was gradually introduced into the above mixture to initiate the polymerization process. It is important to mention that all the aforementioned solutions were pre-cooled to $0-5{ }^{\circ} \mathrm{C}$, and the polymerization process was also conducted at $0-5{ }^{\circ} \mathrm{C}$ for $12 \mathrm{~h}$. Once the polymerization process was finished, there were black powder precipitates. The powders were filtered and washed with de-ionized water and ethanol, and then dried in a vacuum oven at $60{ }^{\circ} \mathrm{C}$ for $12 \mathrm{~h}$.

2.3 Fabrication of slurry-free PPy-sulfur-PPy flexible sandwich electrode: First, the dried PPy free-standing film was cut into circular disks with a diameter of $10 \mathrm{~mm}$. The commercial sulfur and sulfur-PPy fiber composite powder were then dispersed, respectively, onto the disks. Then the two disks containing active materials were piled together and pressed to 40 MPa by a hydraulic hand press to form the PPy-sulfur-PPy sandwich structure electrode. 
After pressing, the two disks adhered together and formed a flexible single sandwich electrode. Then, the disks were heated at $50{ }^{\circ} \mathrm{C}$ for 24 hours under vacuum and transferred into a glove box. The synthesis of the PPy free-standing film and the active material loading process into the PPy-sulfur-PPy sandwich electrode are shown in Figure S1 in the Supporting Information. For fabrication of the sulfur-PPy fiber composite, $10 \mathrm{wt} \%$ PPy fibers were added to the sulfur and hand milled before insertion into the sandwich electrode. The loading of active material in the sandwich electrode was about $3 \mathrm{mg} / \mathrm{cm}^{2}$.

2.4 Fabrication of cells: CR 2032 coin-type cells were assembled in an Ar-filled glove box where oxygen and moisture levels were less than $0.1 \mathrm{ppm}$, and discs of $\mathrm{Li}$ foil were used as the counter electrode and reference electrode. The electrolyte was prepared by dissolving $1 \mathrm{M}$ lithium bis(trifluoromethane sulfonyl)imide (LiTFSI) and $0.1 \mathrm{M} \mathrm{LiNO}_{3}$ in co-solvents of 1,3dioxolane (DOL) and 1,2-dimethoxyethane (DME), with a volume ratio of 1:1. Each cell contains $\sim 100-200 \mu \mathrm{L}$ of electrolyte. A porous polypropylene film was used as the separator.

2.5 Characterization: To characterize the PPy film and Li/S cells, different analytical tools were used. For physical and morphological characterization of the composite, X-ray diffraction (XRD, GBC MMA 017), Raman spectroscopy (JOBIN YVON HR800 Confocal Raman system with $632.8 \mathrm{~nm}$ diode laser excitation on a 300 lines/mm grating at room temperature), and field emission scanning electron microscopy (JEOL: FESEM-7500) were used. A JANDAL instrument, Model RM3, UK was used for measuring the four-probe electrical conductivity. For electrochemical performance evaluation of the Li/S cell, an automatic battery test system (Land ${ }^{\circledR}$, China) was used at various current densities at room temperature. For testing the cycling performance, the conventional voltage window which is 1.5 to $3 \mathrm{~V}$ was applied. Electrochemical impedance spectroscopy (EIS) and cyclic voltammetry (CV) measurements were performed on a Biologic VMP 3 electrochemical 
workstation over a frequency range of $10 \mathrm{mHz}$ to $100 \mathrm{kHz}$, and the scan rate was $0.05 \mathrm{mVs}^{-1}$ within a $1.5 \mathrm{~V}$ to $3 \mathrm{~V}$ voltage window.

\section{Results and Discussion:}

The electrochemical polymerization (EP) of pyrrole is an anodic oxidation reaction where high quality PPy films are usually produced in a three-electrode system, although temperature, solution concentration, anion size, and electrode materials have a significant effect on the PPy film's quality [30]. In our synthesis process, pyrrole is oxidized from a $0.2 \mathrm{M}$ solution of pyrrole in the presence of an organic anion ( $p$-toluene-sulfonate) and deposited on the working electrode (stainless steel plate). The reaction is shown in Scheme1. The oxidation of pyrrole to PPy is irreversible, and its reaction mechanism is controversial, although the most accepted mechanism comprises four steps including monomer oxidation followed by resonance formation, coupling (dimerization of carbon radicals), and chain growth [31].

It has been found that EP method has much greater advantages over conventional chemical synthesis. The most notable advantages of the electro-polymerized PPy film are: high conductivity, and good control of the mass and thickness of the film. Controlling the mass and thickness of the PPy film can dictate its physical and the mechanical properties. It has been observed that PPy films that are less than $1 \mu \mathrm{m}$ in thickness have different spectral properties, depending on the conditions of synthesis and the degree of polymerization [32]. Table1 shows the processing parameters for the EP method along with the physical properties that have been used and observed in this work. The deposition time and current density of the electro-deposition process were varied, while the deposition charge was kept constant for all three samples. The physical characterization shows that there were changes in the PPy film thickness, density, and conductivity with deposition time and current. Figure-1shows the 
differences in PPy film thickness, which were measured from FESEM images. From Table-1, it can be inferred that the deposition current density is proportional to the film thickness and inversely proportional to the density and conductivity of the film. (The measurements of density and conductivity are explained in detail in the Supporting Information).

The discrepancies in the properties of PPy films can be explained in this way. At lower current density, the deposition time was longer, which allowed polymer chains to pile up in a more orderly and compact way than with higher current density and shorter deposition time. Due to high compactness and the ordered form of polymer chains, sample-a showed lower thickness and higher density. On the other hand, the opposite properties were observed for sample-c, whereas sample-b stands in between these two with moderate density and thickness. The conductivity of the films is also related to density. Higher density PPy films should show higher conductivity than lower density ones due to the easier movement of delocalized $\pi$-electrons [33]. Table- 1 also support this argument where sample-a shows the maximum conductivity and sample-c shows the minimum. It is important to note, however, that sample-b, which was fabricated using $1 \mathrm{~mA} / \mathrm{cm}^{2}$ current density and 4 hours deposition time, shows $8.55 \mathrm{~S} / \mathrm{cm}$ lower and $24.83 \mathrm{~S} / \mathrm{cm}$ higher electronic conductivity than that of sample-a and sample-c, respectively, although the deposition time difference between sample-a and sample-b is four hours. It can be deduced from Table1 that, sample-b is a more commercially favorable and scalable film than the remaining two.

The XRD pattern which is shown in Figure-2a indicates the amorphous nature of the PPy films by showing a diffuse broad band in the curves. It was calculated that the electrodeposited PPy films show upto 15\% crystallinity with monoclinic lattice structure [27]. A little hump at $20^{\circ}$ in the XRD patterns confirms the presence of a minor percentage of crystalline domains in the bulk amorphous PPy. The intensity of the humps for sample-a and sample-b appears slightly higher than for sample-c, implying that the contents of crystalline 
domains are comparatively higher in sample-a and sample-b than in sample-c. The XRD results support the properties of PPy films that are stated in Table-1, where it was claimed that sample-a and sample-b have more compact and dense structures than sample-c. The Raman spectrum for all three samples is shown in Figure-2b where all the samples show similar characteristic peaks of PPy. The peak around $1570 \mathrm{~cm}^{-1}$ is attributed to the backbone stretching mode of the $\mathrm{C}=\mathrm{C}$ bond. A broad ring stretching mode is observed around $1370 \mathrm{~cm}^{-}$ ${ }^{1}$ to $1380 \mathrm{~cm}^{-1}$. The most important peak is observed at $1230 \mathrm{~cm}^{-1}$, however, which is attributable to $\mathrm{N}-\mathrm{H}$ in plane bending mode and is the finger print of PPy. Beside these, two more peaks were observed which represent $\mathrm{C}-\mathrm{H}$ in plane deformation at $933 \mathrm{~cm}^{-1}$ to $1046 \mathrm{~cm}^{-}$ ${ }^{1}[10,34]$.

After confirmation from XRD and Raman spectroscopy that the synthesized films are PPy with mostly amorphous structure, it is now important to emphasize the morphology of the film. This is because the morphology of the film will dictate the flexibility, electrochemical performance, and active material content of the cell. Figure-3 shows the morphology of all three samples, and a systematic trend is observed. All the images show a cauliflower-like corrugated structure, but for the samples grown at higher current density, the "flowers" are larger and more intense than for growth at lower current density. It is important to remember here that, although the current density varies, the total charge remains constant regardless of the deposition time for all the samples. Asavapiriyanont et al.[31] first discovered the PPy film formation process, which is similar to the conventional metal solidification process, based on a nucleation and growth mechanism. By using his idea, it is possible to describe the morphological change in the PPy film when different current density is applied.

At higher current density, polymer chains have less time to form nucleation sites on the steel plate, so the polymer chains pile onto a limited number of nucleation sites and form a large and intense cauliflower structure. On the other hand, at low current density, great numbers of 
nucleation sites evolve, and the polymer chains have plenty of time to find suitable nucleation and growth sites to form a uniformly distributed film with less intense cauliflower shapes. It is worth mentioning that the cauliflower corrugated surface morphology is necessary for loading sulfur (active material) onto the film. The valley between successive cauliflowers can accommodate large amounts of active materials. On the other hand, these highly intense cauliflowers have some shortcomings during the fabrication of the slurry-free sandwich electrode. These cauliflowers prevent two films from adhering together when mechanical force is applied. As discussed earlier, it is possible to manipulate the morphology of the PPy film by changing the processing parameters of the electro-deposition process, which is one of the most influential reasons for choosing the electro-deposition method over chemical methods for PPy film fabrication. Figure-3b shows that, at moderate current density (1 $\mathrm{mA} / \mathrm{cm}^{2}$ ), we can obtain an optimum morphology with a sufficient number of peaks and valleys to load the desired amount of active material along with better adhesion between films when mechanical force is applied. It can be concluded from the physical and morphological properties of PPy films that sample-b is appropriate for loading the active material and for fabricating flexible PPy-sulfur-PPy sandwich electrode. In the next part of this paper we will only focus on the sample-b PPy film for fabrication and performance evaluation of PPy-sulfur-PPy sandwich electrode, which was synthesized using $1 \mathrm{~mA} / \mathrm{cm}^{2}$ current density and 4 hours deposition time.

Figure-4a and $4 \mathrm{~b}$ respectively shows the elemental sulfur and sulfur-PPy composite that were loaded into sandwich electrodes. Figure-4b also shows that the PPy fibers, which have a very high aspect ratio wrap up the sulfur particles completely, which will have a definite positive affect towards utilization of the active materials during electrochemical testing. Figure-4c, which is a high magnified version the indicated area of Figure-4b clearly shows that the PPy fibers which have greater length and smaller diameter, (high aspect ratio) have a favorable 
geometry for wrapping sulfur particles. This sulfur-PPy hand-milled composite was also characterized by FESEM while an energy dispersive spectroscopy (EDS) detector was inserted. The element maps shown from Figure-4d through Figure-4g confirm the successful wrapping of sulfur by PPy a fiber, which is also reconfirmed by the multi-point elemental analysis shown in Figure-4h, where peaks from all the investigated elements are detected.

Figure-S2 shows a split half top view and a cross sectional view of sandwich electrode. The split half structure confirms that the sulfur-PPy composite has been distributed on and covers the smooth portion of the PPy film, and the cauliflower like peaks remain uncovered. There is significant importance to those peaks. When two split half structures are piled onto each other, and then subjected to $40 \mathrm{MPa}$ pressure to form a sandwich structure, those peaks help to maintain a gap between those two split halves. This tiny gap may help to percolate electrolyte to come and contact with the active materials hence better electrochemical performance is expected. The cross-sectional view of the sandwich electrode in Figure-S2 confirms the gap between the two split halves. After characterizing the fabricated PPy films, sulfur-PPy composite, split half structure, and PPy-sulfur-PPy sandwich electrode, it is important to evaluate the electrochemical performance. The PPy-sulfur-PPy sandwich electrode was coupled with metallic lithium enable observations of the cycling performance, rate capability, cyclic voltammograms (CV), and electrochemical impedance spectra (EIS).

Figure-5a shows the cycling performance of sandwich electrodes containing elemental sulfur and sulfur-PPy composite as active materials. The sandwich electrode having elemental sulfur active material shows an initial capacity of $804 \mathrm{mAh} / \mathrm{g}$ and managed to retain 247 mAh/g after 400 cycles. On the other hand, the sandwich electrode containing sulfur-PPy active material shows an initial discharge capacity of $790 \mathrm{mAh} / \mathrm{g}$ and has a capacity of 383 mAh/g after 500 cycles. Both electrodes show a very stable and high coulombic efficiency 
around $94 \%$. The capacity loss for the sulfur-PPy containing sandwich electrode is $0.103 \%$ per cycle, whereas $0.173 \%$ per cycle is lost for the elemental sulfur containing sandwich electrode, which is about $68 \%$ higher capacity loss than that of sulfur-PPy containing sandwich electrode. This is presumably because of higher active material utilization due to the addition of $10 \mathrm{wt} \%$ PPy fibers, which helped to increase the conductivity of the insulating sulfur. Another important factor that needs to be considered is that the PPy films contain nitrogen. It is well-established that nitrogen-doped materials can successfully capture the polysulfides in the lithium-sulfur system, which helps to increase the capacity retention of that system [35]. A similar explanation is also applicable for our work, where nitrogencontaining PPy films can capture the polysulfides and can reduce the well-known shuttle phenomenon problem, resulting in better capacity retention or lower capacity fading. A similar argument can be applied to the rate capability results, which are shown in Figure-5b. The results show that the sandwich electrode containing sulfur-PPy active material has a higher discharge capacity at different current densities and better reversible capacity than of the pure-sulfur-containing sandwich electrode. The galvanostatic charge-discharge plateaus in Figure-5c,d also support the claim by showing low polarization at higher current densities.

Figure-S3 shows the $1^{\text {st }}$ cycle charge-discharge profile of both active materials containing sandwich electrodes. The profile shows two discharge plateaus and one charge plateau at $2.3 \mathrm{~V}, 2.05 \mathrm{~V}$ and $2.38 \mathrm{~V}$, respectively. The most important phenomenon that needs to be considered here is the potential difference between the charge plateau and the discharge plateau. The sulfur-containing electrode shows a declining discharge difference, which means a higher value of concentration polarization, activation polarization, and internal resistance (IR) drop. The sandwich electrodes containing $10 \mathrm{wt} \%$ PPy fibers show a stable charge and discharge plateau, indicating low concentration polarization, activation polarization, and $I R$ drop. In another sense, it can be said that with addition of PPy fibers the conductivity 
increases and facilitates electron diffusion, which reduces the internal resistance and polarization potential, respectively.

Figure-6a and 6d shows cyclic voltammograms of sandwich electrodes containing sulfur and sulfur-PPy for the first 4 cycles with a scan rate of $0.05 \mathrm{mV} \mathrm{s}^{-1}$. Both sets of voltammograms show two reduction peaks at $2 \mathrm{~V}$ and $2.2-2.3 \mathrm{~V}$ along with one oxidation peak at 2.3-2.4V, with a major deviation in the intensity. The sulfur-containing sandwich electrode exhibits lower current during oxidation than that of sulfur-PPy sandwich electrode, which is also a definite proof of higher active material utilization in the sulfur-PPy electrode than in the sulfur electrode. The first reduction peak at 2.2-2.3 $\mathrm{V}$ appeared due to the change of elemental sulfur to long chain lithium polysulfide $\left(\operatorname{Li}_{2} S_{n}, n \geq 4\right)$, and the second reduction peak appearing at 1.9-2.0 V reflects the reduction of long chain lithium polysulfides to short chain lithium polysulfides $\left(\mathrm{Li}_{2} \mathrm{~S}_{\mathrm{n}}, n<4\right)$. The intensity of both reduction peaks for sulfur-PPy composite is higher than for elemental sulfur, which indicates less reversible discharge capacity for the elemental sulfur than the sulfur-PPy sandwich electrode [36]. It should be mentioned that the oxidation peak of the sulfur-PPy electrode shows a broad shoulder compare to the elemental sulfur electrode. This phenomenon can be explained as follows. For the first few cycles, the sulfur may not have sufficient contact with the electrolyte due to the wrapping with PPy fibers, which slows the oxidation process. As a result of this, a broad peak appears in the oxidation curve rather than the sharp peak that appears for the elemental sulfur electrode. This assumption is also confirmed by the cycling performance curve (Figure-5a), where the discharge capacity gradually increases over first few cycles for the sulfur-PPy electrode, while the opposite trend occurs for the sulfur electrode.

The EIS results shown in Figure-6b, 6c and 6e, 6f present the impedance spectra for the sandwich electrodes with both the sulfur electrode and the sulfur-PPy composite before and after cycling. Figure-6b, 6c and 6e, $6 \mathrm{f}$ also show the Z-fitted equivalent curves of both 
sandwich electrodes. The Z-fitted equivalent curves contain the resistance (R), a constant phase element $(\mathrm{CPE} \approx C)$, and the Warburg impedance element $(\mathrm{W}) . \mathrm{R}_{1}$ and $\mathrm{R}_{2}$ represent the solution resistance of the electrolyte, and the charge transfer resistance including surface resistance, respectively. The CPE is related to the solid-state diffusion of $\mathrm{Li}^{+}$due to the formation of a double layer capacitor between the electrolyte and the cathode interface. $\mathrm{W}$ is the Warburg impedance element attributable to the diffusion of lithium ions in the active materials.

The Z-fitted EIS results for both the elemental sulfur and the sulfur-PPy electrodes before and after cycling are listed in Table-2. The solution resistance for both electrodes increases after cycling, although the increment for elemental sulfur is much higher than that of the sulfurPPy electrode. Moreover, the increase in the solution resistance after four cycles is very small for the sulfur-PPy electrode, although for the elemental sulfur-based composite, the solution resistance increases by more than 7 times after four cycles. The increased solution resistance occurs due to the dissolution of polysulfide into the electrolyte after several cycles. For the case of the sulfur-PPy electrode, few polysulfides may be captured by PPy a fiber, which reduces the electrolyte resistance compared to the elemental sulfur electrode. The charge transfer resistance and the constant phase element of both the sulfur electrode and the sulfurPPy electrode are decreased after four cycles, which indicates better movement of $\mathrm{Li}^{+}$ions from the anode to the cathode. Another important parameter that can be extracted from Table 2 is the Warburg impedance element (W). The Warburg impedance is higher for the sulfur electrode compared to the sulfur-PPy electrode. This means that the diffusion of $\mathrm{Li}^{+}$from the electrolyte-cathode interface to the active material is easier for the sulfur-PPy electrode and difficult for the elemental sulfur electrode. After four cycles, the Warburg impedance value increases for both; although the increment is larger for the elemental sulfur electrode which 
confirms that the solid electrolyte interphase (SEI) for the elemental sulfur is much thicker compared to the sulfur-PPy electrode and impedes $\mathrm{Li}^{+}$diffusion.

It can be inferred from the above discussion that the addition of $10 \mathrm{wt} \%$ PPy fibers has a significant effect towards the utilization of a high amount of active material, as well as capturing polysulfides. It is important to remember here that the main purpose of this work is to use free-standing PPy film for making slurry-free sandwich electrodes that will have better structural stability and will reduce the well-known shuttle phenomenon. The electrochemical performance and morphological study showed that the PPy-sulfur-PPy sandwich electrode can achieve better capacity by minimizing those aforementioned limitations. Nevertheless, a final task is yet to be done for confirmation of electrode stability after cycling. This confirmation is important to justify the flexible electrode phenomena that can ameliorate the volume expansion problem of sulfur during discharging. To prove the stability of the PPy films after cycling, it is necessary to investigate the after cycling morphology of the PPy film. Figure-S4 shows the FESEM image of the electrode after cycling and it clearly indicates that the PPy film still remains integrated and stable after cycling. No cracks or tattered portions were detected apart from the porosity, which was created due to the movement and diffusion of $\mathrm{Li}^{+}$ions as well as percolation of electrolyte that contains dissolved polysulfides.

\section{Conclusion:}

A PPy free-standing film was synthesized through the electro-polymerization method. The morphological structure was modified by changing the deposition time and current density, while the charge density remained constant. The synthesized PPy film has very high conductivity along with a corrugated structure and was directly used to load slurry-free active material and was integrated into a self-supported PPy-sulfur-PPy sandwich electrode. The fabricated sandwich electrode shows an initial discharge capacity of $804 \mathrm{mAh} / \mathrm{g}$ and has a 
capacity of $247 \mathrm{mAh} / \mathrm{g}$ after 400 cycles with 93\% coulombic efficiency. After the addition of $10 \mathrm{wt} \%$ PPy fiber to the sulfur the retained capacity was $383 \mathrm{mAh} / \mathrm{g}$ after 500 cycles, representing $0.103 \%$ capacity loss per cycle, which is $67 \%$ lower compare to bare sulfur. It is worthwhile mentioning here that the active material loaded in this work was $100 \%$ sulfur (elemental sulfur) and 90\% sulfur (10\% PPy fiber), which is the second highest percentage of active material so far that has been reported. Only recently did Manthirum's group [37] load more active materials than in this work. They limited the number of cycles to 200, however, whereas in this work we report 500 cycles.

\section{Acknowledgement:}

The authors gratefully acknowledge the support provided by the Commonwealth Scientific and Industrial Research Organisation (CSIRO) and the University of Wollongong. The authors also thank Dr. Tania Silver for critical reading of the manuscript.

\section{References:}

[1] M. Armand, J.M. Tarascon, Nature 451(7179) (2008) 652-657.

[2] P.G. Bruce, S.A. Freunberger, L.J. Hardwick, J.-M. Tarascon, Nat Mater 11(1) (2012) 1929.

[3] X. Ji, K.T. Lee, L.F. Nazar, Nat Mater 8(6) (2009) 500-506.

[4] Y.Z. Song, W. Zhao, L. Kong, L. Zhang, X.Y. Zhu, Y.L. Shao, F. Ding, Q. Zhang, J.Y. Sun, Z.F. Liu, Energ Environ Sci 11(9) (2018) 2620-2630.

[5] Y.Z. Song, W. Zhao, N. Wei, L. Zhang, F. Ding, Z.F. Liu, J.Y. Sun, Nano Energy 53 (2018) 432-439.

[6] Y.Z. Song, W. Zhao, X.Y. Zhu, L. Zhang, Q.C. Li, F. Ding, Z.F. Liu, J.Y. Sun, Acs Applied Materials \& Interfaces 10(18) (2018) 15733-15741. 
[7] M.R. Kaiser, J. Wang, X. Liang, H.-K. Liu, S.-X. Dou, Journal of Power Sources 279(0) (2015) 231-237.

[8] M.R. Kaiser, X. Liang, K. Konstantinov, H.-K. Liu, S.-X. Dou, J.-Z. Wang, Chemistry A European Journal 21(28) (2015) 10061-10069.

[9] X. Liang, M. Kaiser, K. Konstantinov, R. Tandiono, Z. Wang, H.-K. Liu, S.-X. Dou, J. Wang, RSC Advances 4(69) (2014) 36513-36516.

[10] X. Liang, M. Zhang, M.R. Kaiser, X. Gao, K. Konstantinov, R. Tandiono, Z. Wang, H.K. Liu, S.-X. Dou, J. Wang, Nano Energy 11(0) (2015) 587-599.

[11] M.R. Kaiser, S. Chou, H.K. Liu, S.X. Dou, C.S. Wang, J.Z. Wang, Adv Mater 29(48) (2017).

[12] M.R. Kaiser, Z. Han, J. Liang, S.-X. Dou, J. Wang, Energy Storage Materials 19 (2019) $1-15$.

[13] M.R. Kaiser, X. Liang, H.-K. Liu, S.-X. Dou, J.-Z. Wang, Carbon 103 (2016) 163-171.

[14] M.R. Kaiser, Z.H. Ma, X.W. Wang, F.D. Han, T. Gao, X.L. Fan, J.Z. Wang, H.K. Liu, S.X. Dou, C.S. Wang, Acs Nano 11(9) (2017) 9048-9056.

[15] F. Li, M.R. Kaiser, J. Ma, Z. Guo, H. Liu, J. Wang, Energy Storage Materials 13 (2018) 312-322.

[16] X. Liang, M.R. Kaiser, K. Konstantinov, R. Tandiono, Z. Wang, C. Chen, H.-K. Liu, S.X. Dou, J. Wang, ACS Applied Materials \& Interfaces 8(38) (2016) 25251-25260.

[17] J. Zheng, M. Gu, M.J. Wagner, K.A. Hays, X. Li, Journal of the Electrochemical Society 160(10) (2013) A1624-A1628.

[18] K. Xi, P.R. Kidambi, R. Chen, C. Gao, X. Peng, C. Ducati, S. Hofmann, R.V. Kumar, Nanoscale 6(11) (2014) 5746-5753.

[19] C. Wang, X. Wang, Y. Yang, A. Kushima, J. Chen, Y. Huang, J. Li, Nano Letters 15(3) (2015) 1796-1802. 
[20] W. Li, Q. Zhang, G. Zheng, Z.W. Seh, H. Yao, Y. Cui, Nano Letters 13(11) (2013) $5534-5540$.

[21] J. Yang, J. Xie, X. Zhou, Y. Zou, J. Tang, S. Wang, F. Chen, L. Wang, The Journal of Physical Chemistry C 118(4) (2014) 1800-1807.

[22] C. Wang, K. Su, W. Wan, H. Guo, H. Zhou, J. Chen, X. Zhang, Y. Huang, Journal of Materials Chemistry A 2(14) (2014) 5018-5023.

[23] F. Wu, S. Wu, R. Chen, J. Chen, S. Chen, Electrochemical and Solid-State Letters 13(4) (2010) A29-A31.

[24] F. Wu, J. Chen, L. Li, T. Zhao, R. Chen, The Journal of Physical Chemistry C 115(49) (2011) 24411-24417.

[25] Y. Yang, G. Yu, J.J. Cha, H. Wu, M. Vosgueritchian, Y. Yao, Z. Bao, Y. Cui, ACS Nano 5(11) (2011) 9187-9193.

[26] J. Wang, J. Chen, K. Konstantinov, L. Zhao, S.H. Ng, G.X. Wang, Z.P. Guo, H.K. Liu, Electrochim Acta 51(22) (2006) 4634-4638.

[27] V.V. Tat'yana, N.E. Oleg, Russian Chemical Reviews 66(5) (1997) 443.

[28] J.-Z. Wang, S.-L. Chou, H. Liu, G.X. Wang, C. Zhong, S. Yen Chew, H. Kun Liu, Materials Letters 63(27) (2009) 2352-2354.

[29] H. Zhao, W.E. Price, G.G. Wallace, Journal of Membrane Science 148(2) (1998) 161172.

[30] R.E. Noftle, D. Pletcher, Journal of Electroanalytical Chemistry and Interfacial Electrochemistry 227(1-2) (1987) 229-235.

[31] S. Asavapiriyanont, G.K. Chandler, G.A. Gunawardena, D. Pletcher, Journal of Electroanalytical Chemistry and Interfacial Electrochemistry 177(1-2) (1984) 245-251.

[32] F. Croce, S. Panero, S. Passerini, B. Scrosati, Electrochim Acta 39(2) (1994) 255-263. [33] J. Heinze, Synthetic Metals 43(1-2) (1991) 2805-2823. 
[34] F. Chen, J. Zhang, F. Wang, G. Shi, Journal of Applied Polymer Science 89(12) (2003) 3390-3395.

[35] G. Qi, L. Huang, H. Wang, Chemical Communications 48(66) (2012) 8246-8248.

[36] X. Liang, Z. Wen, Y. Liu, H. Zhang, L. Huang, J. Jin, Journal of Power Sources 196(7) (2011) 3655-3658.

[37] L. Qie, A. Manthiram, Adv Mater 27(10) (2015) 1694-1700. 


\section{Figures and Schemes}

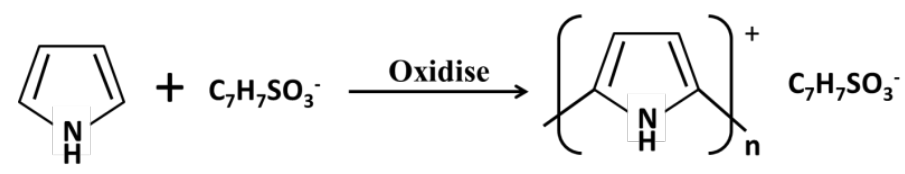

Scheme-1: PPy formation reaction via electrochemical polymerization of Py.

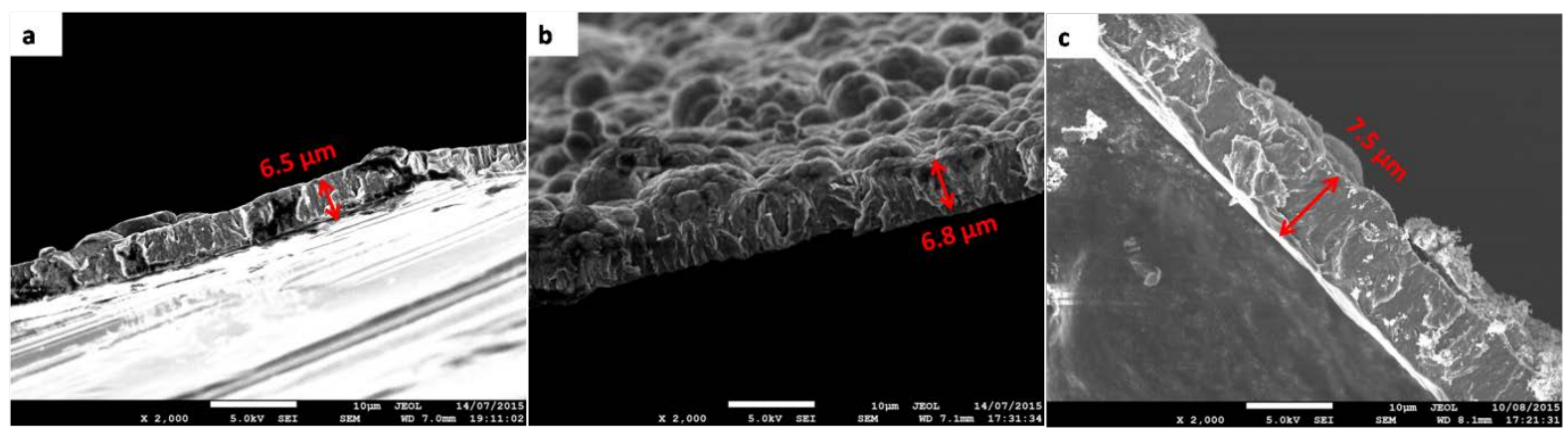

Figure-1: Determination of PPy film thickness from FESEM images where a) represents sample-a, b) represents sample-b and c) represents sample-c. 

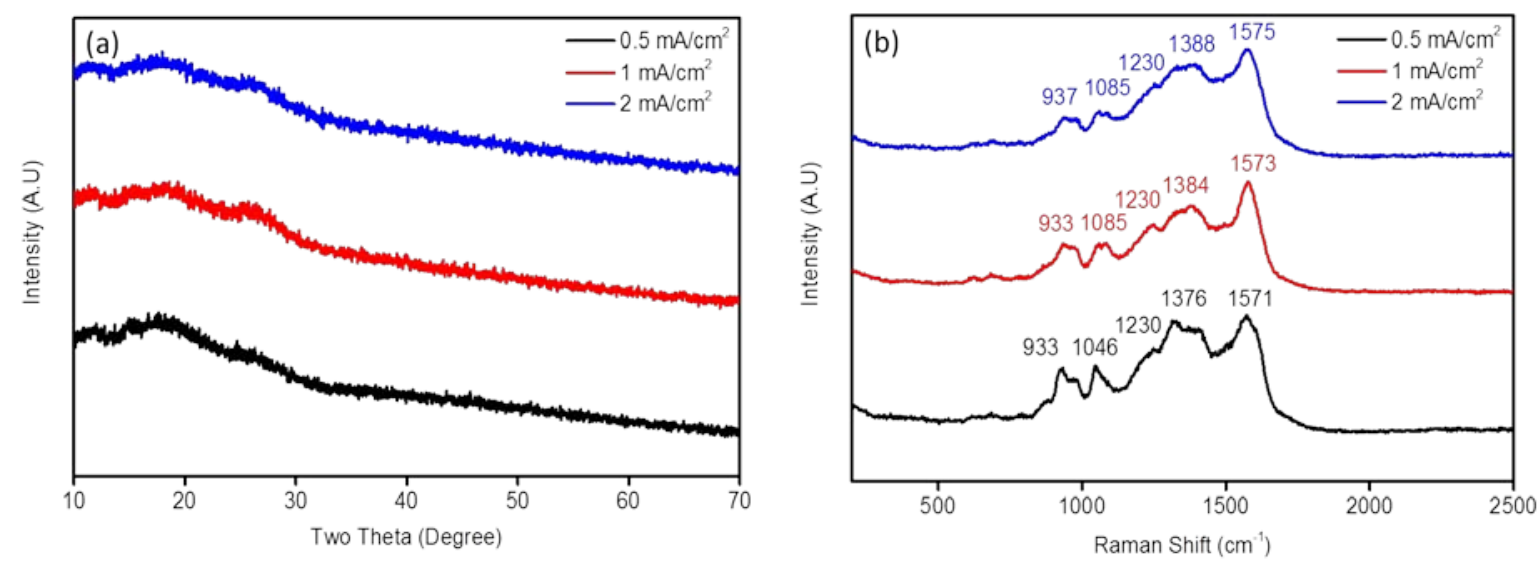

Figure 2: a) XRD patterns and b) Raman spectra of PPy films grown with different deposition current densities.
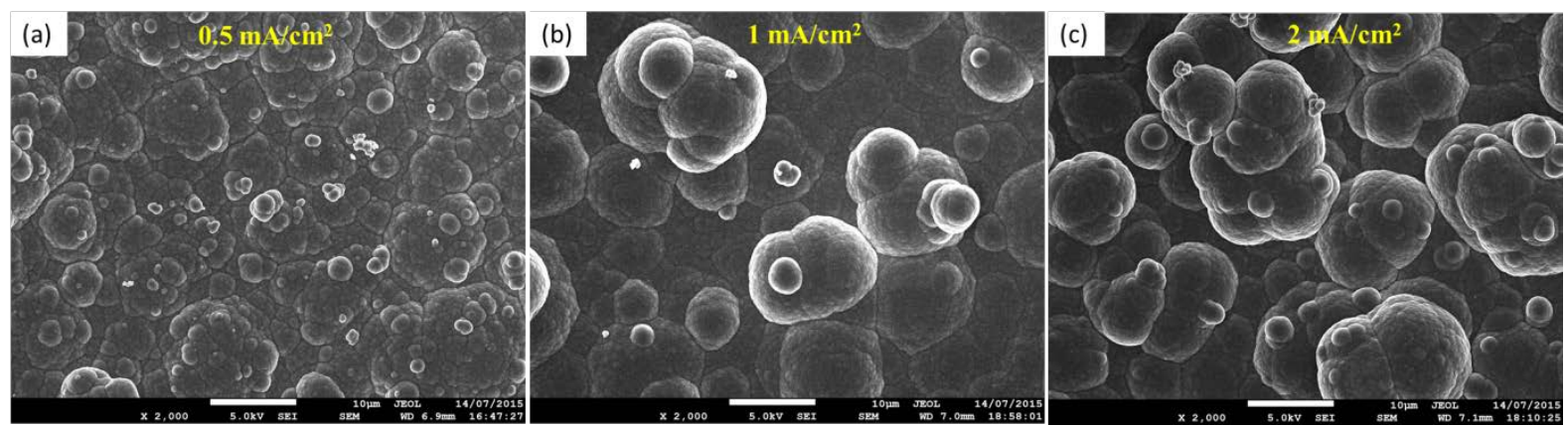

Figure 3: FESEM images of a) sample-a b) sample-b and c) sample-c. 


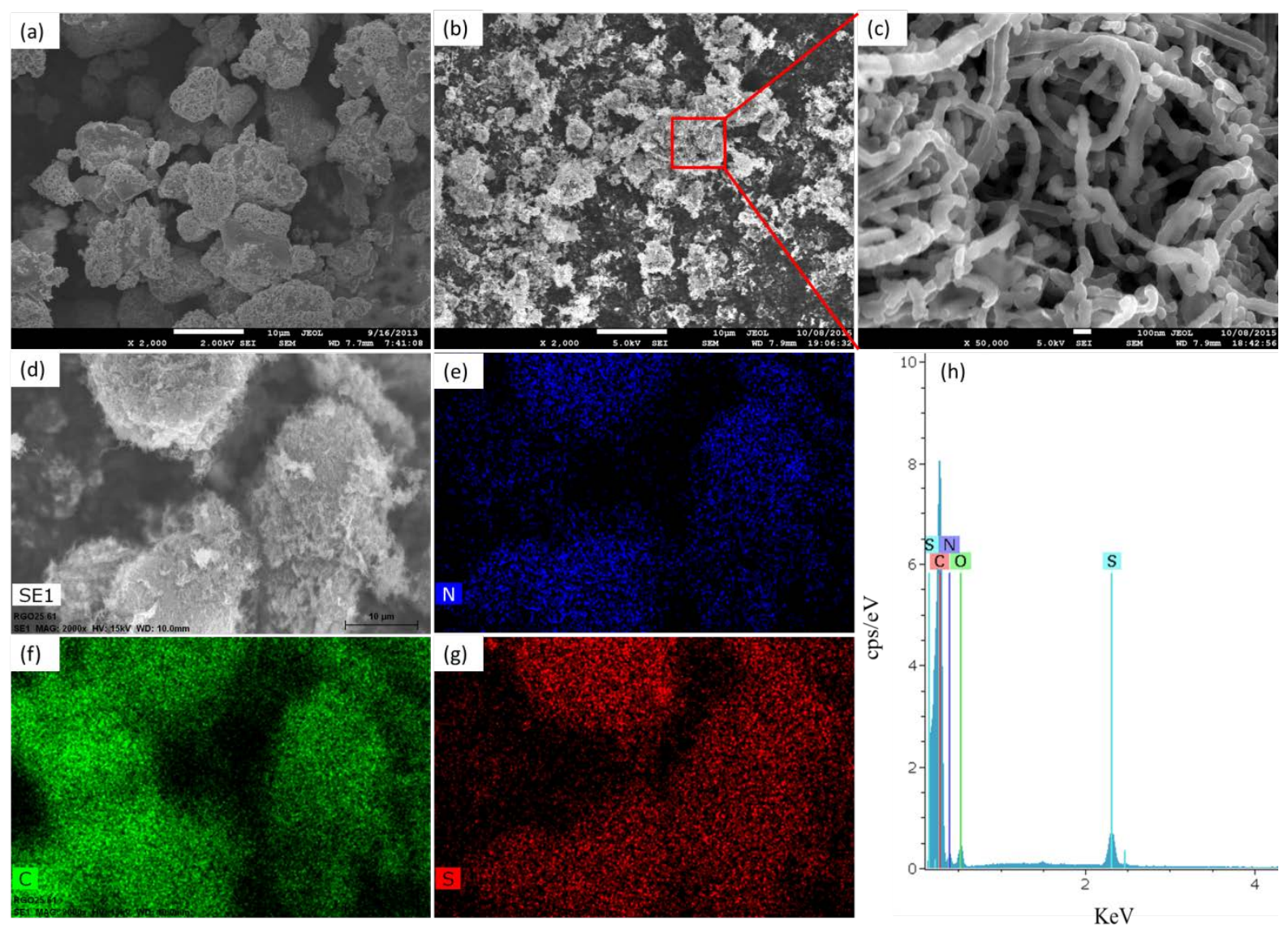

Figure 4: FESEM image of a) elemental sulfur b,c) sulfur-PPy composite at low and high magnification. d-g) EDS mapping of sulfur-PPy composite and h) multi-point elemental analysis of sulfur-PPy composite. 

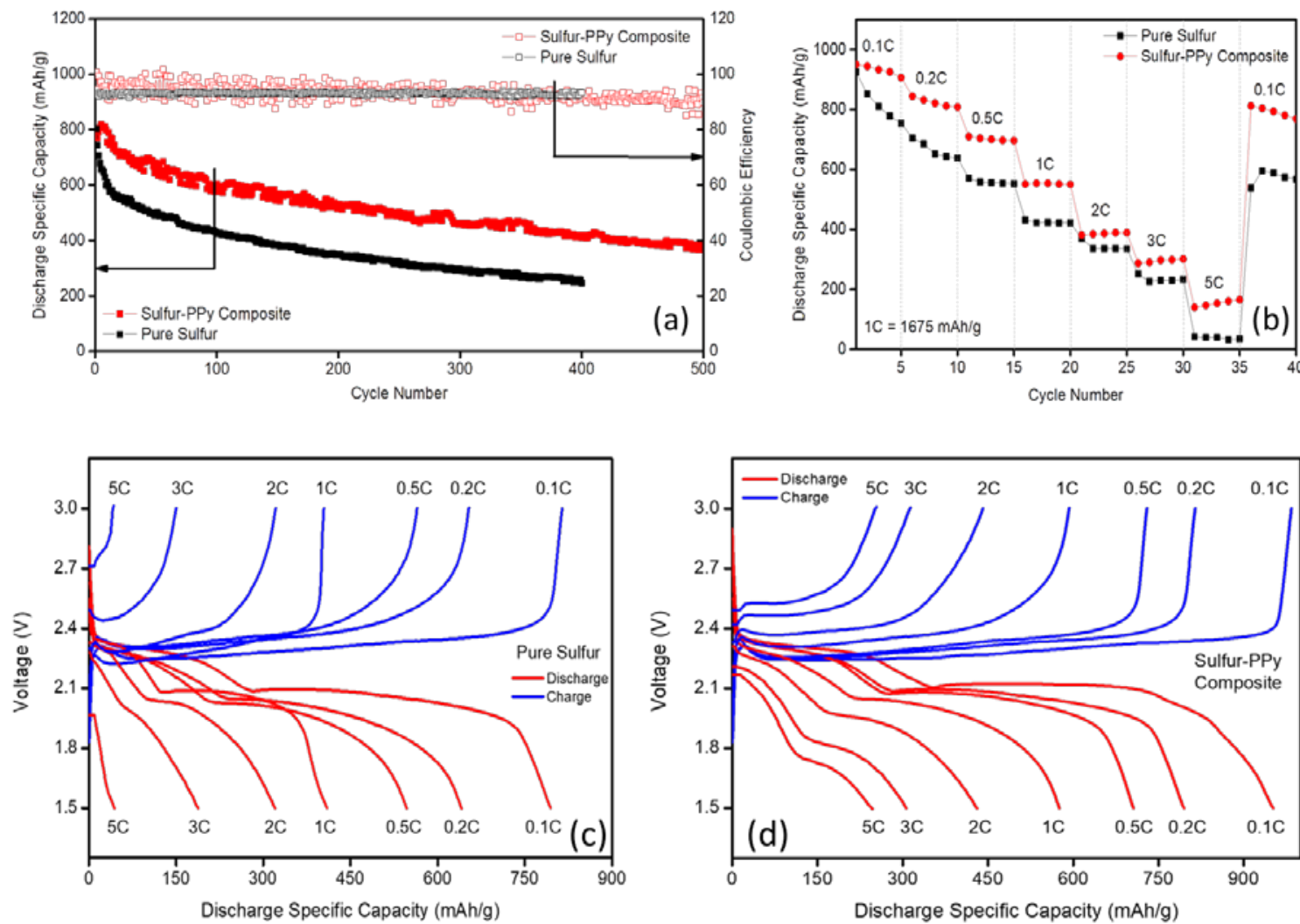

Figure 5: a) Cycling performance at $0.1 \mathrm{C}$ and b) rate capability and c,d) galvanostatic chargedischarge curves of pure sulfur-based electrode and sulfur-PPy-based sandwich electrode. 

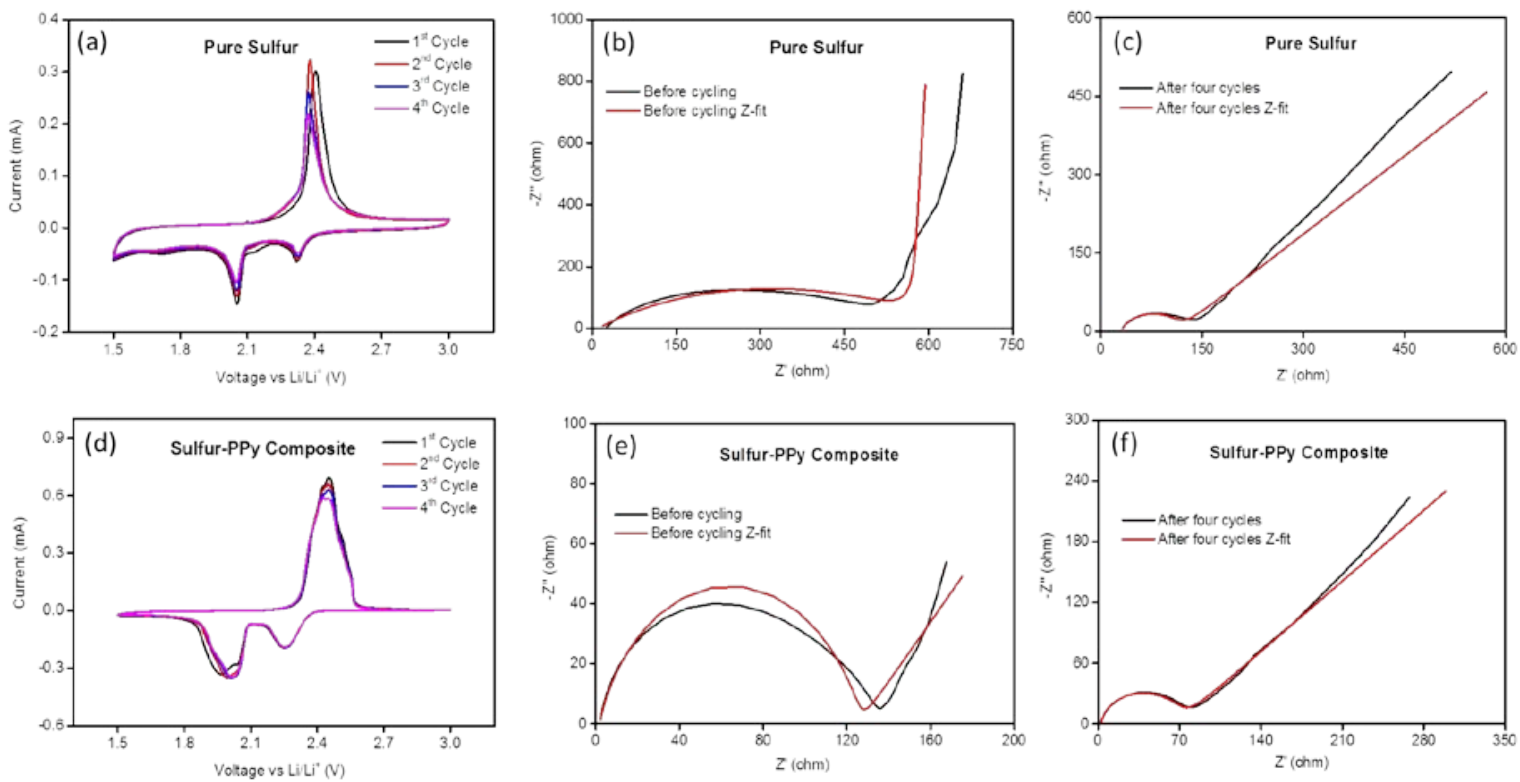

Figure 6: a,d) Cyclic voltammograms for the first 4 cycles, b,e) EIS spectra before cycling, and c,f) EIS spectra after cycling of sandwich electrodes containing pure sulfur (top) and sulfur-PPy composite (bottom). 


\title{
Supporting Information
}

\section{Synthetization of Electropolymerized Polypyrrole Film for Fabrication of Slurry-free Polypyrrole-Sulfur-Polypyrrole Sandwich Electrode for the Lithium-Sulfur Battery}

\author{
Mohammad Rejaul Kaiser ${ }^{\mathrm{a}, \mathrm{b} *}$ Zhaojun Han ${ }^{\mathrm{a}, \mathrm{c}, \mathrm{d}}$, Jiazhao Wang ${ }^{\mathrm{b} *}$ \\ ${ }^{\text {a }}$ CSIRO, Manufacturing, P.O. Box 218, 36 Bradfield Road, Lindfield, NSW 2070, Australia. \\ ${ }^{\mathrm{b}}$ Institute for Superconducting and Electronic Materials, University of Wollongong, \\ Wollongong, NSW 2522, Australia \\ c School of Chemical Engineering, The University of New South Wales, Kensington, New \\ South Wales 2052, Australia. \\ ${ }^{\mathrm{d}}$ School of Mechanical and Manufacturing Engineering, The University of New South \\ Wales, Kensington, New South Wales 2052, Australia
}

*Correspondence address: rejaul.kaiser@csiro.au

jiazhao@uow.edu.au 


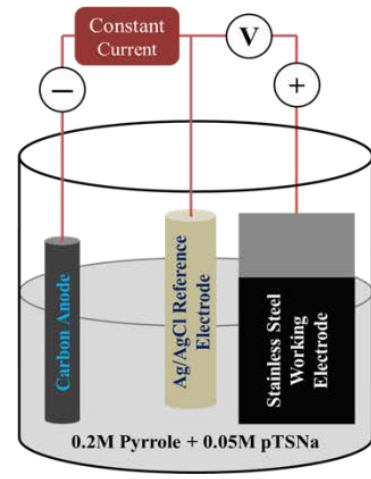

Schematic view of PPy electrodeposition

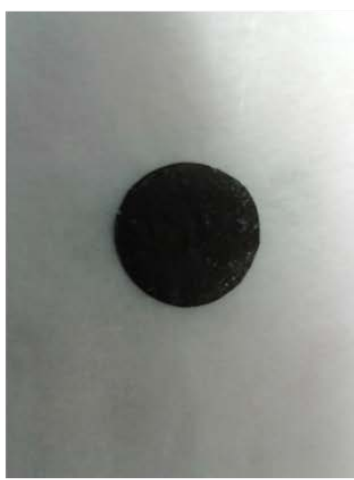

Slurry-less PPy-S-PPy sandwich electrode

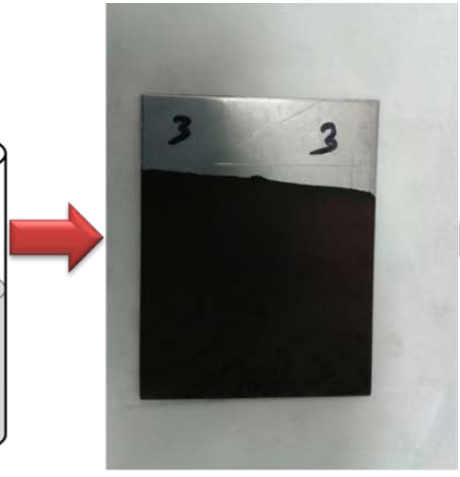

Electro-deposition of PPy on working electrode

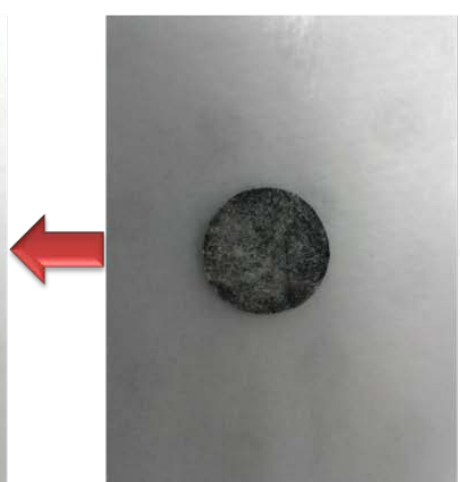

Active material loading into PPy electrode disc

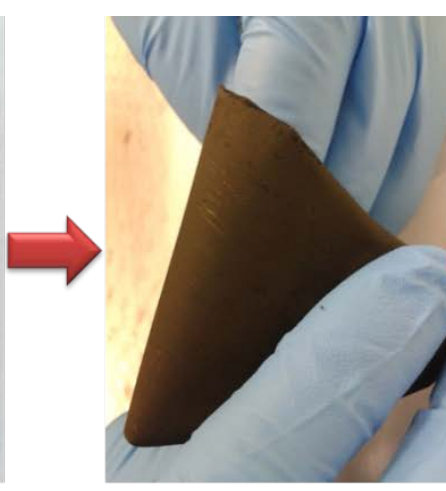

Peeled off PPy freestanding layer

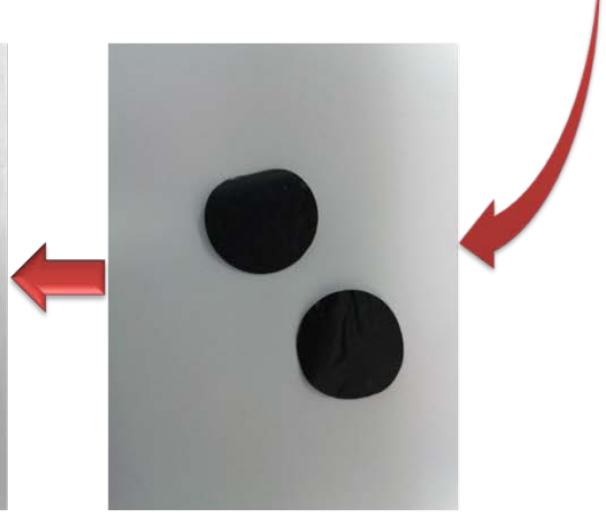

PPy layer cut into electrode disc size

Figure S1: Steps involved in the synthesis of PPy free-standing film and the fabrication of PPy-sulfur-PPy sandwich electrode.

\section{Density measurements:}

The density of the fabricated PPy film was measured by using the following formula:

$\rho=m / v$

Here, $m=$ mass of the film (measured by using balance), $v=$ volume of the film.

The volume of the film is measure by using the following equation:

$V=\pi r^{2} h$ 
Here, $r=$ radius $(5 \mathrm{~mm}$ ), $h=$ thickness of the film (measured by using scanning electron microscope)

\section{Density measurement for sample-a( $\left.\rho_{\mathrm{a}}\right)$ :}

$m=0.71 \mathrm{mg}$

$v=\pi r^{2} h=3.1416 \times(0.5)^{2} \times 6.5 \times 10^{-4}=5.105 \times 10^{-4} \mathrm{~cm}^{3}$

$\rho_{\mathrm{a}}=1.39 \mathrm{gm} / \mathrm{cm}^{3}$

Similarly,

$\rho_{\mathrm{b}}=1.37 \mathrm{gm} / \mathrm{cm}^{3}$

$\rho_{\mathrm{c}}=1.32 \mathrm{gm} / \mathrm{cm}^{3}$

\section{Four probe electrical conductivity measurement:}

The conductivity of the PPy film was measured by using the following equation:

$\sigma=(1 / R) / h$

Here, $R$ = resistance, which was measured by the four probe JANDEL RM 3, UK, instrument.

$h=$ Thickness of the film

Conductivity measurement for sample-a $\left(\sigma_{a}\right)$ :

$R=25.84 \Omega$

$h=6.5 \times 10^{-4} \mathrm{~cm}$

$\sigma_{\mathrm{a}}=(1 / 25.84) / 6.5 \times 10^{-4}=59.53 \mathrm{~S} / \mathrm{cm}$

Similarly,

$\sigma_{\mathrm{b}}=50.98 \mathrm{~S} / \mathrm{cm}$

$\sigma_{\mathrm{c}}=26.15 \mathrm{~S} / \mathrm{cm}$ 

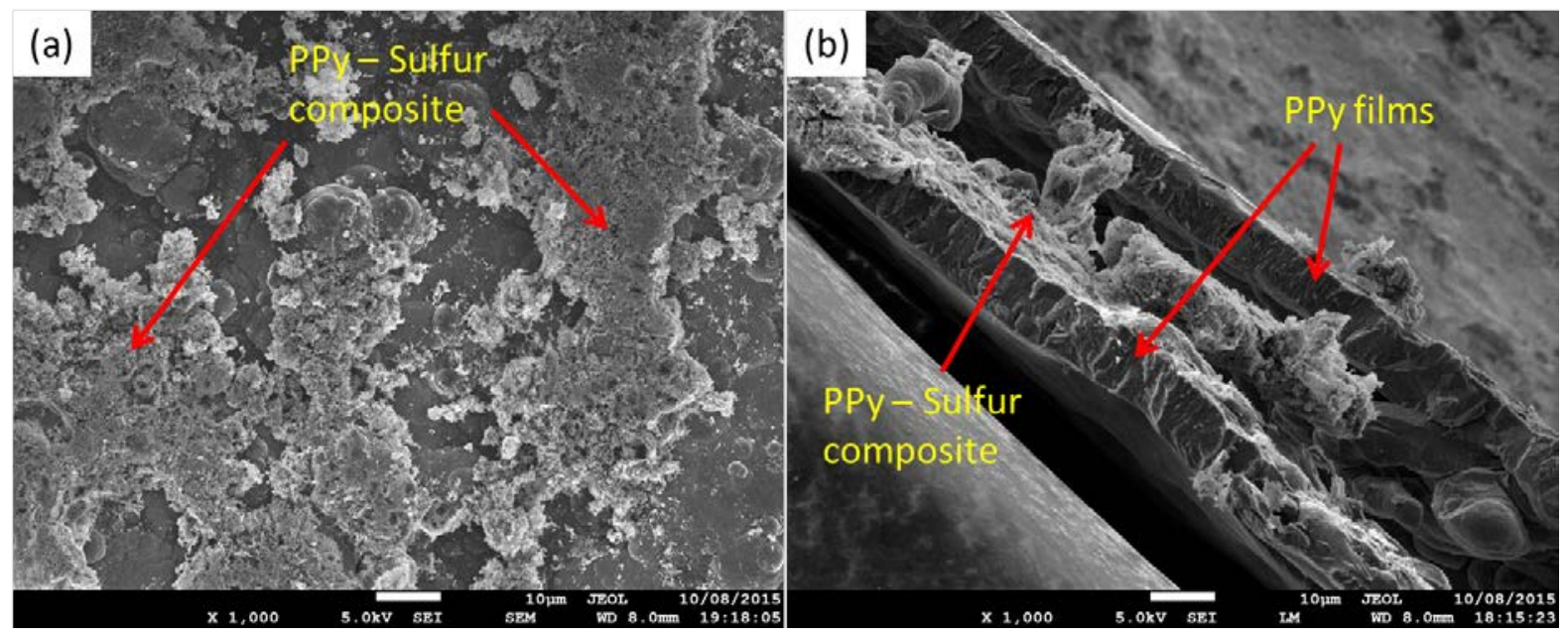

Figure S2: FESEM images for a) sulfur-PPy composite loading onto a PPy film; b) crosssectional view of PPy-sulfur-PPy sandwich electrode.
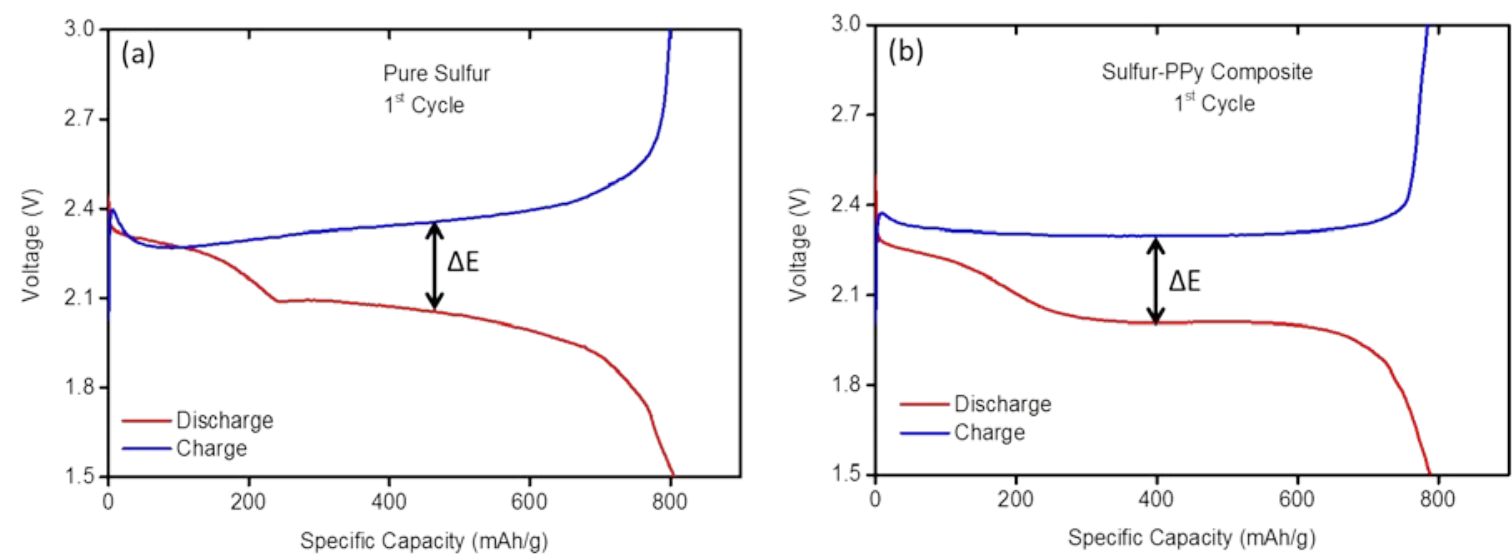

Figure S3: $1^{\text {st }}$ cycle charge-discharge profile. 


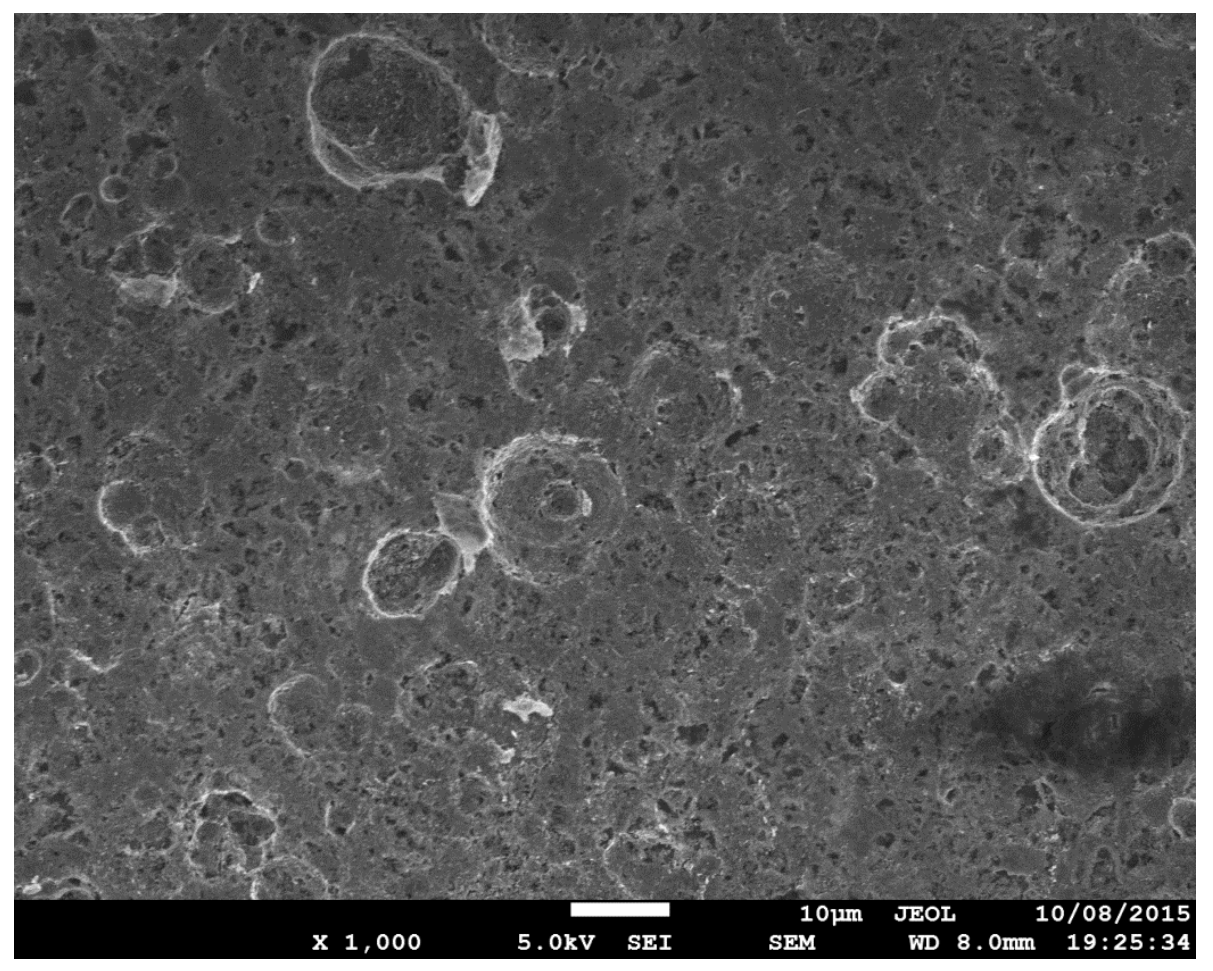

Figure S4: FESEM image of PPy film after cycling. 
Tables

Table 1: Processing parameters and physical properties of PPy film.

\begin{tabular}{|c|c|c|c|c|c|c|}
\hline Sample & $\begin{array}{c}\text { Deposition } \\
\text { Current } \\
\left(\mathrm{mA} / \mathrm{cm}^{2}\right)\end{array}$ & $\begin{array}{l}\text { Deposition } \\
\text { Time (h) }\end{array}$ & $\begin{array}{c}\text { Deposition } \\
\text { Charge } \\
\left(\mathrm{C} / \mathrm{cm}^{2}\right)\end{array}$ & $\begin{array}{l}\text { Thickness } \\
\text { of the PPy } \\
\text { film }(\mu \mathrm{m})\end{array}$ & $\begin{array}{c}\text { Density of } \\
\text { the PPy film } \\
\qquad\left(\mathrm{g} / \mathrm{cm}^{3}\right)\end{array}$ & $\begin{array}{l}\text { Conductivity } \\
\text { (S/cm) }\end{array}$ \\
\hline $\mathrm{a}$ & 0.5 & 8 & 14.4 & 6.5 & 1.39 & 59.53 \\
\hline $\mathrm{b}$ & 1 & 4 & 14.4 & 6.8 & 1.37 & 50.98 \\
\hline C & 2 & 2 & 14.4 & 7.5 & 1.32 & 26.15 \\
\hline
\end{tabular}


Table 2: Z-fitted value of EIS spectra for both pure sulfur and sulfur-PPy composite containing sandwich electrodes.

\begin{tabular}{|c|c|c|c|c|c|}
\hline & Impedance values & $\mathrm{R}_{\mathrm{e}}(\Omega)$ & $\mathrm{R}_{\mathrm{ct}}(\Omega)$ & $\mathrm{CPE}(\mu \mathrm{F})$ & $\mathrm{W}\left(\Omega . \mathrm{S}^{-0.5}\right)$ \\
\hline \multirow{3}{*}{ Pure sulfur } & Before cycling & 4.81 & 625.80 & 90.86 & 37.80 \\
\cline { 2 - 6 } & After cycling & 30.17 & 85.38 & 3.57 & 453.30 \\
\hline \multirow{2}{*}{$\begin{array}{c}\text { Sulfur-PPy } \\
\text { composite }\end{array}$} & Before cycling & 1.69 & 124.40 & 12.24 & 12.32 \\
\cline { 2 - 6 } & After cycling & 2.39 & 67.12 & 4.01 & 227.70 \\
\hline
\end{tabular}




\section{Highlights:}

- Electro-polymerization PPy free-standing films with tuneable thickness.

- $\quad$ Slurry-free active material processing.

- Direct loading of high amount commercial sulfur $\left(\sim 3 \mathrm{mg} / \mathrm{cm}^{2}\right)$.

- Metal current collector, Binder and additives-free active material processing.

- Very low capacity fading ( 0.103\% capacity loss per cycle). 


\section{Graphical Abstract}

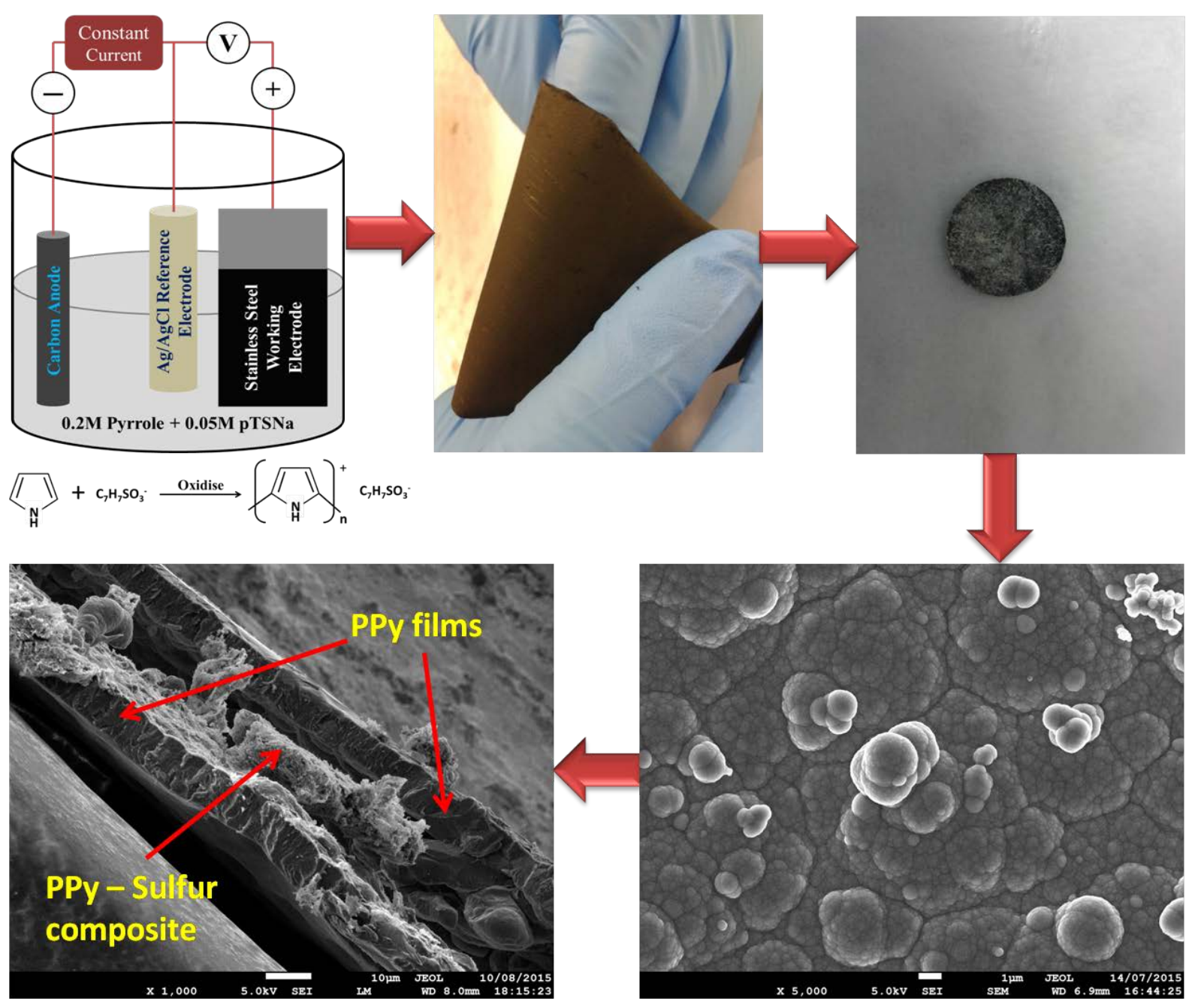

